\section{China plays cards close to its chest over manned space shot}

\section{David Cyranoski, Beijing}

China is expected to attempt to send its first man into space later this month, sources say. But analysts have warned that the mission may be postponed by managers of China's military-run space programme.

A successful launch of the Shenzhou 5 space capsule would make China the third nation to send a human into orbit - and set up China's emerging space programme for a twenty-first-century rivalry with that of the United States.

Government officials and semiofficial sources have suggested throughout the year that the flight is due to take place in the middle of this month, but no official date has been released. Phillip Clark, head of the UK-based Molniya Space Consultancy, speculates that China will announce the flight at very short notice and air it live on television.

But even basic details of the flight, such as the number of 'taikonauts' who will be on board, have remained closely guarded. An official at one Chinese spaceresearch organization says that, for safety reasons, only a single person will ride in the three-seat launch vessel. "This will be a symbolic flight," the official says.

But Clark suggests that China might try to send more than one person into space, to get one-up on the initial, solo flights by the Soviet Union and the United States, four decades ago.

Many of China's space scientists and engineers consider the space programme to be a scientific one, even though it falls within the military budget. They want to see an end to US export-control rules that block collaboration with NASA and exclude China from the International Space Station project.

A success with Shenzhou 5 might move China towards its goal of having its own space station, observers of the programme say. The next step would be to carry out docking exercises between a Shenzhou craft and another orbital module.

China's manned space programme has been progressing slowly — it is already four years since the country launched its first unmanned space capsule. But time is not a pressing issue for the Chinese space programme, comments Brian Harvey, a space analyst based in Ireland. "It is a slow, determined and stable programme," he says. "They aren't racing against anybody.”

\section{NIH 'roadmap' charts course to tackle big research issues}

Erika Check, Washington

The director of the US National Institutes of Health (NIH) has announced a long-term plan for the biomedical research agency in which its component institutes will join forces to tackle priority projects.

The NIH Roadmap, released by director Elias Zerhouni on 30 September, was developed by NIH institute directors and outside experts. Zerhouni says the $\mathrm{NIH}$ will begin implementing the plan in 2004, at an initial cost of $\$ 125$ million, rising rapidly to $\$ 2$ billion by 2009 .

The plan includes 28 programmes in three main categories: new technologies, new types of research team and ways to improve clinical research infrastructure. NIH institutes will contribute from their individual budgets to support the programmes. "For the first time, there's been a real change in the way institutes fund common projects, because every institute has agreed to contribute to this common fund," Zerhouni says.

The plan will move the NIH along the road to supporting 'big' biology. For instance, the structural-biology programme calls for scientists to find new ways to produce large amounts of membrane-bound proteins and study them in a systematic way. Currently, there is no good way to isolate and study such proteins.

Another programme will set up libraries and databases of small molecules to be studied as potential drug treatments, and a third will create centres to write software for the analysis of biological data.

Another aim will be to build teams of investigators from diverse backgrounds: a series of programmes and conferences will foster collaborations between biologists and physical scientists. The roadmap also contains plans for the training of clinical researchers and for centres of excellence in translational research - the interface between lab work and patient care.

Zerhouni says the Roadmap is an attempt to address scientific problems that the NIH has struggled with in the past, such as multidisciplinary projects that require many institutes to work together. He acknowledged scientists' fears that biology research has shifted away from investigations by individuals, towards large, technology-driven science.

"Our sense from talking to the community is that we need to create new modes of exploration because the scale and complexity of scientific problems has increased," Zerhouni says. "That's what we're doing and we'll find out what the results are soon."

David Korn of the Association of American Medical Colleges says: "Universities, scientists and journals are all going to have to adjust to the multidisciplinary mode of science, and this plan moves in the right direction. But it's going to be a very unsettling change."

\title{
Ion-powered probe set for year-long Moon trek
}

\section{Geoff Brumfiel}

The first European spacecraft to visit the Moon was launched on 28 September. The craft is using an ion-powered thruster - an experimental propulsion system that the European Space Agency (ESA) hopes will carry probes to other planets.

The craft, called Small Missions for Advanced Research in Technology 1 (SMART-1), blasted off aboard an Ariane 5 rocket from French Guiana. It will now slowly spiral towards the Moon, without the use of typical chemical propellants.
When it arrives, SMART-1 will map the distributions of various elements on the lunar surface, says mission scientist Sarah Dunkin of the UK's Rutherford Appleton Laboratory: "It will help us distinguish between theories of the Moon's creation.”

The ion thruster can only push the $367-\mathrm{kg}$ craft with a force equivalent to a sheet of paper resting on an open hand. The journey will take a year and a quarter, rather than the few days taken by the Apollo missions. But given its bargain price of $\mathrm{E} 100$ million (US\$120 million), ESA is willing to wait. 